E.L.U.A., 1, 1983, págs. 249-262

\title{
MECANISMOS DE IDENTIFICACIÓN Y NEXUACIÓN COMPLEJA EN LA DINÁMICA TEXTUAL
}

\author{
Estanislao Ramón Trives \\ (Universidad de Murcia)
}

0 . Parto del principio-hipótesis de que la lengua, en cualquiera de los niveles de su comportamiento, está condicionada por la alteridad, una suerte de customary connexion a lo Hume-Nietzsche, donde la lengua, la verdad, "es aquella clase de error sin la cual no puede vivir una especie determinada", pues en efecto, la lengua, como la verdad orteguiana, es "cosa humana, demasiado humana. Ser verdad es parecerle a uno verdad». (Cf. J. Ortega y Gasset, Obras Completas, Alianza Editorial, Madrid, 83, vol. 12, pág. 417). Todo elemento lingüístico lo es en cuanto que funciona, siendo el prototipo del objeto estructural, "correlato específico de una conciencia compositiva o sintética». (lb., pág. 379). En el auténtico hablar no sólo «somos humildes rehenes del pasado" (lb., vol. V, pág. 448), sino inexorables protagonistas del futuro, dado que, basándonos nuevamente en Ortega - modesto homenaje centenario-, el "buen conservador", como "el escritor en algún buen sentido de la palabra, implica que ha usado su lengua con un prodigioso tacto, logrando dos cosas que parece imposible cohonestar: ser inteligible, sin más, y a la vez modificar el uso ordinario del idioma» (lb., vol. V, pág. 435). Lo que justifica, lapidariamente, Ortega de la siguiente forma: "Cuando la conversación no es mero canje de mecanismos verbales en que los hombres se comportan casi como gramófonos, sino 
que los interlocutores hablan de verdad sobre un asunto, se produce un curioso fenómeno. Conforme avanza la conversación, la personalidad de cada uno se va disociando progresivamente: una parte de ella atiende a lo que se dice y colabora al decir, mientras la otra, atraída por el tema mismo, como el pájaro por la serpiente, se retrae cada vez más hacia su íntimo fondo y se dedica a pensar en el asunto. Al conversar vivimos en sociedad: al pensar nos quedamos solos. Pero el caso es que en ese género de conversaciones hacemos ambas cosas a la vez..." (lb., vol. V, pág. 437, subrayado nuestro).

1.1. El ordenamiento sintagmático-textual es un auténtico trabajo pluriestructural, donde la lectura-captura de la inveterada experiencia de una comunidad, que resulta ser la lengua, adquiere un nuevo sesgo en la inexorable rebeldía o afirmación del individuo frente a su grupo, en un particular engarce de similitudes y diferencias en convergencia macroestructural, en una especie de nuevo "ordo ordinem ordinans" agustiniano, "parium dispariunque rerum sua cuique loca tribuens dispositio". El virtuosismo del individuo frente a las expectativas del código sociolingüístico multilectal que justifica al hablante en cuanto tal, puede ponerse de relieve especialmente a la hora de saturar y focalizar el argumento del módulo proposicional enunciativo en función de las distintas fases del flujo discursivo oral o escrito. En efecto, las expectativas del código aumentan o disminuyen, orientan su incidencia funcional hacia una construcción u otra, en función de la dialéctica o retórica discursivas, el marco pragmalingüístico, etc. Véase, por ejemplo, cómo desde la complicidad enunciado/enunciación, en el sentido de que todo lo que es dicho o escrito es enunciado, que, a su vez, remite a una fuerza enunciativa personal o enunciación, que al ser explícita pasa a ser enunciado, subsecuente, la cual, asimismo, remite a su correspondiente fuerza enunciativa personal o enunciación, en un encadenamiento sin fin, donde las distintas piezas argumentales basculan de un marco de operatividad a otro en función de la fuerza enunciativa, dentro de los mecanismos de puesta en discurso; en un microtexto como

ENTRO EN CLASE

se puede plantear como argumento del movimiento-núcleo proposicional el móvil y el término del movimiento, dejando para una segunda fase de modalización la adscripción del sintagma EN SERIO, que funciona como modalizante del enunciado anterior, modalizado, como argumento de la modalización o relación argumental entre elementos pertenecientes a la misma clase o en rección genérica mutua, en con- 
traste con el enunciado anterior, donde se plantea una rección argumental especifica:

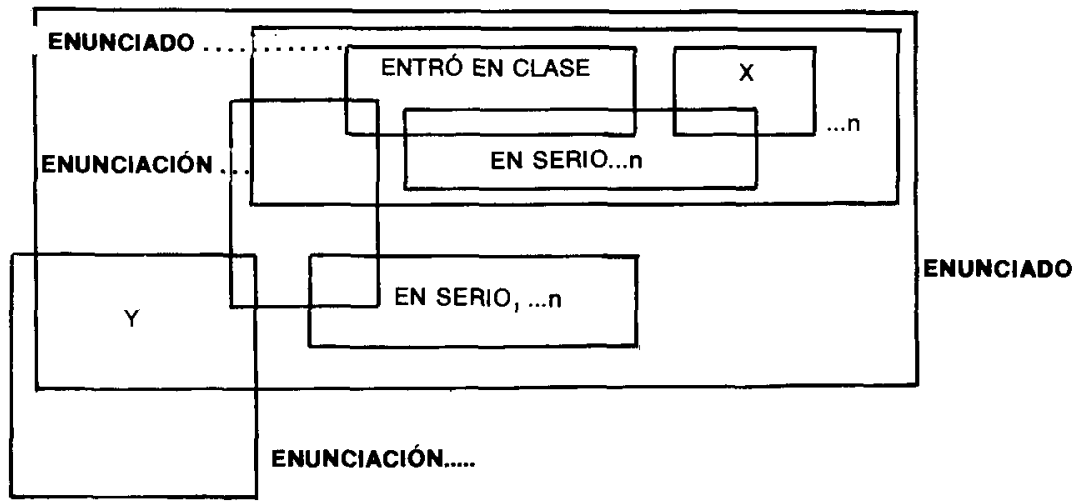

donde caben distintos matices de adscripción de la incidencia del sintagma EN SERIO, según que el hablante modalice el enunciado dominante ENTRO EN CLASE, o la enunciación expresa o enunciada, modalizando el enunciado del enunciado, EN SERIO', o la enunciación, en fin, en una serie recursiva, subyacente, responsable último de todo lo explícito en el discurso, en cualquiera de sus niveles.

1.1.1. La elección de la incidencia del modalizante EN SERIO, en el microtexto arriba propuesto, escapa a las previsiones del sistema, cuyas virtualidades actualizan e identifican los mecanismos de puesta en discurso de acuerdo con un proyecto pre-resultativo-resultativo, que siquiera sea como método hipotético-deductivo, es lícito plantear, como se desprende de la observación de Aristóteles, en su Retórica, I, 33 y ss.: "Y lo que origina algo es de tres maneras: una, como el tener salud origina la salud; otra, como los alimentos originan la salud; y otra, como el hacer gimnasia, que en general origina la salud. La retórica es correlativa de la dialéctica, pues ambas tratan de cosas que en cierto modo son de conocimiento común a todos y no corresponden a ninguna ciencia determinada $<\ldots>$ Y la gente, unos lo hacen al descuido y otros mediante la costumbre que resulta de hábito. Mas puesto que cabe de ambas maneras, es evidente que se podria trazar también para 
estas cosas un camino; pues la causa porque aciertan, tanto los que siguen un hábito como los que obran al descuido, cabe estudiarla, y todos reconocerán que tal estudio es una tarea de un arte. Puesto que es evidente que el método conforme a arte se refiere a los argumentos retóricos, y los argumentos retóricos son una especie de demostración (pues prestamos crédito sobre todo cuando entendemos que algo está demostrado), la demostración retórica es un entimema (el cual es, por decirlo en general, el más fuerte de los argumentos) y el entimema es un silogismo." (Subrayado nuestro).

Lo que, evidentemente, nos hace ver que las unidades discursivas son multifrontes, dado que vertebran características propias del acervo virtual multilectal lingüístico, por un lado, junto con la memoria que incide en dichas unidades discursivas, en virtud del desarrollo textual antecedente, por otro, así como las tentativas hipotético-deductivas, que es lícito y necesario emitir en el proyecto de lectura del desarrollo textual subsecuente; $y$ todo ello en función de la fuerza argumental que las identifica en su particular fuerza expresiva. Toda unidad lingüistica al incidir en la textura sintagmática del discurso se convierte en algo relativo, funcional, argumental, en mayor o menor grado, en un ton

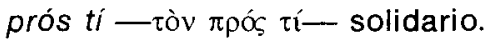

1.2. La lengua como aglutinante social intersubjetivo, en su capacidad de instrumentación múltiple, adaptable a todas las vivencias y situaciones, tiene como salvaguarda de la eficacia de su condición económica la "estructura», y como motor de su operatividad creativo-comunicativa la condición «abierta», dinámica, de ese acervo estructurado precisamente. La lengua no es una "Substantia» con una plasmación estructural conclusa, sino un devenir, una "historia» no conclusa, historia compartida y abierta, en su haber-sido y en su persistente capacidad de-ser. Esa es la grandeza y servidumbre de nuestra lengua, ése su atractivo como objeto de estudio. La lengua no es una piedra o cristal, objeto unitario e inerte de investigación —en la medida en que el estado de la ciencia de hoy permitiera esa expresión-, es, más bien, como la vida, un resultado dialéctico, abierto y plegado, como la piel a su propio cuerpo, a las prerrogativas de cada grupo o individuo en cada momento.

2. Los mecanismos de identificación son como los diques de contención que aseguran que la multiplicidad de posibilidades que emanan de 
la condición abierta de las estructuras lingüísticas, cristalicen en texto, con una estructura terminal dada, cerrada o abierta, pero intencionalmente dada, a la postre, como piedra de toque incuestionable de una multiplicidad de interpretaciones, en la medida en que el texto utiliza a la lengua (potencial interpretativo cerrado del texto) o, por el contrario, el texto es lengua, en su más íntima razón de ser (potencial interpretativo abierto del texto creativo o artístico-literario).

2.1. Pero el texto, en cuanto articulado, reclama la diversidad como razón de su existencia también. En este sentido, nos encontramos con mecanismos que interrumpen el flujo isotópico discursivo y lo encaminan por otros derroteros, haciendo patente la intencionalidad enunciativa, tanto en un sentido explícito (mediante conmutadores específicamente distópicos), como en un sentido/inducido o implícito (mediante estructuras distópicas, donde se trasluce la intencionalidad irónica, lamentativa, etc., del sujeto de la enunciación). El hecho de que en determinadas lenguas coexistan ambos tipos de nexuación puede ser una confirmación evidente de lo que venimos diciendo. Piénsese en las estructuras siguientes:

—N'est-il pas venu? // Ist er nicht angekommen?

-(Mais) si! // (Aber) doch!

donde tanto el «si!» francés como el «doch!» alemán conectan con la voz del sujeto de la enunciación, contraria a lo enunciado en la frase inmediata anterior.

2.2. Los mecanismos de identificación pueden ser considerados tanto en su incidencia exodeíctico-endodeíctica (comunicación textual), como en su incidencia estrictamente endodeíctica (creación textual). Los operadores deicticos espacio-temporales (e inclusive los modales) fijan, en su monovalencia operativa, el sentido unitario del texto desde la plurivalencia significativa de la lengua. En la medida en que dichos operadores se desvinculan de la realidad extralingüistica, las piezas y/o estructuras lingü isticas mantienen toda su capacidad decidora, de máxima operatividad en la creación estético-literaria. 
3. La economía de la lengua exige, a mi juicio, tanto la estructura como la apertura o variación, en una dialéctica ininterrumpida. En efecto, la condición instrumental de la lengua en el proceso intersubjetivo comunicativo exige la estructura como condición intrínseca del funcionamiento intersubjetivo sobre la base de unas claves estructuradas comunes. Lo cual es económico. Pero la sistemática estructural cerrada incidiria en el contrasentido del axiomatismo absoluto de las “lenguas formalizadas», siendo, evidentemente, lengua natural, y, por lo mismo, no formalizada. La propia economía de la lengua natural exige la "apertura" de su necesaria «estructuración», quedando así instrumento dúctil y maleable en función de la variada estructura experiencial, variable, a su vez, como es obvio, en función de registros de las más variadas características, psicológicas, sociológicas, etc., etc.

3.1. Como ejemplo de variación o acomodación de la «estructura semio-sintáctica” de la lengua, podemos reparar en el siguiente texto de Conversación en La Catedral, de Mario Vargas Llosa, página 329:

Ambrosio se había sentado en la cama revuelta, $y$, entre sus lagrimones, Amalia lo veía mover la cabeza, no entiendes, no me comprendes... El torció la boca, se le habían saltado los ojos, botó el pucho al suelo y lo aplastó. Amalia tenía su orguIlo, no me vas a engañar dos veces, y él la miró con ansiedad: si ése no se hubiera muerto te juro que lo mataba, Amalia. Ahora sí se iba a atrever, ahora sí. Si, se paró de un salto, y a cualquier otro que se le cruzara también, y lo vio acercarse decidido, con la voz un poco ronca: porque tú eres mi mujer mujer, eso lo vas a. No se movió, dejó que la cogiera de los hombros y entonces lo empujó con todas sus fuerzas...»

donde, evidentemente, sólo el perfecto plegado de las estructuras de lengua a las exigencias de la situación psicosocial de los interlocutores puede dar razón de la perfecta «normalidad» de una práctica lingüística como la arriba mencionada. En efecto, esa variación de estilos elocutivos, pasando del directo al indirecto libre, o las frases truncadas como "eso lo vas a." no tienen más explicación de su «normalidad» que en la presión de lo extralingüístico sobre lo lingüístico, en una afirmación del carácter subsidiario de la lengua con respecto a la intencionalidad. 
3.2. Los mecanismos de identificación son operadores de los que se vale el hablante movido por su intencionalidad, para la variación que todo texto impone a la sistemática estructural relativa de la lengua, no se pierda en lo incomunicable de lo puramente personal o en la inasible vaguedad designativo-referencial de lo puramente lingüístico. No en vano ya señalaba A.-J. Greimas, en su Maupassant. La sémiotique du texte: exercices pratiques, eds. du Seuil, París, 1976, pág. 266:

...la permanencia del discurso parece reposar, en gran medida, sobre los procedimientos de anaforización, tanto gramaticales como semánticos, que se presentan como aplicaciones del principio general de expansión y de condensación semánticas, que organizan toda la productividad lingüística: son como el pulso rítmico del texto en su manifestación terminal, y funcionan como relevos de la "memoria textual» y garantizan en todo momento la conservación de las adquisiciones semánticas del discurso.

3.3. Ciertamente, como hace ver K. Bühler, en su Teoría del Lenguaje, pág. 466, «la mostración anafórica no puede considerarse en modo alguno como absolutamente imprescindible; pero es muy eficaz y en más de un aspecto extraordinariamente caracteristica del lenguaje». En este sentido, podemos afirmar que determinadas manifestaciones textuales se pueden tipologizar y diferenciar entre sí en función de la generosidad o parvedad en el empleo de los mecanismos de identificación, como lo pone de manifiesto Jenny Simonin-Grumbach, en «Pour une typologie des discours", págs. 85-121, en Langue, discours, société. Pour Émile Benveniste, bajo la dir. de J. Kristeva y otros. E. du Seuil, 1975.

3.3.1. Como también puso de manifiesto $K$. Bühler, o.c., pág. 466 , «vale la pena y es instructivo estudiar las diversas técnicas de composición; pues el que las conoce vuelve a encontrar muchas cosas en el lenguaje y muchas veces bastan también perfectamente para el lenguaje los medios de composición no anafóricos", que podemos centrar en torno a los diversos tipos de isotopía estructural, composicional o no anafó- 
rica; pero, en el grado que la planificación textual exija, nos es preciso acudir a otro tipo de isotopía no estructural o composicional, que actúa deícticamente, y que he llamado «isotopía por identificación».

3.3.1.1. Partimos de la base de que cualquier unidad lingüística puede ser identificada, pero vamos a contemplar en este lugar únicamente las categorias que pueden tener alguna función actancial o predicacional. En este sentido, los tipos de isotopía textual, para atenernos a los registros fundamentales, pueden ser los siguientes:

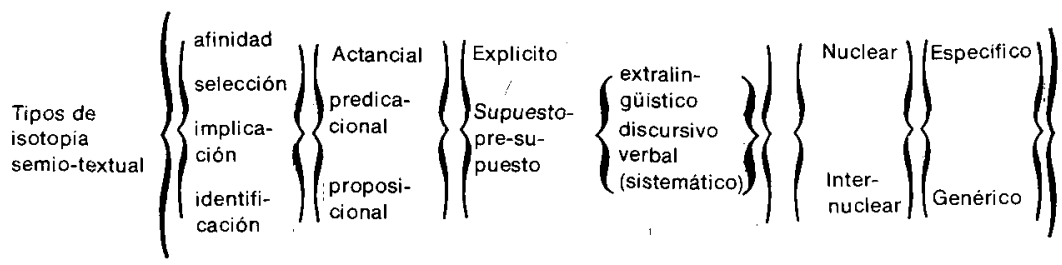

Donde se evidencia cómo por cada registro de caracterización global se pueden dar $\mathbf{4 8}$ tipos isotópicos semio-textuales al amparo, bien de la estructura composicional, afinidad/selección/implicación - solidaridades léxicas de E. Coseriu-, bien mediante mecanismos de identificación correferencial. En estos últimos la fuerza o razón isotópica no procede de un semiotipo composicional o estructura! compartido en mayor o menor grado, según se contemple el despliegue clasificatorio estructural en estadios de complejidad lexémica, archilexémica o clasemática, que aseguran el caudal del flujo discursivo; el semiotipo de los mecanismos de identificación no comparte con las unidades identificadas sino su comportamiento funcional, y en su poder anafórico endodiscursivo y extradiscursivo sirve de cauce fundamental al caudal del flujo discursivo en función de la intencionalidad del hablante, quien, en la medida en que pretenda preservar el valor unitario de su mensaje, en un sentido monovalente, acotará perfectamente el cauce del fluir del sentido de su discurso, mediante las coordenadas de identificación personales, espacio-temporales y modales, evidenciando quién/a quién, el dónde, el cómo y el cuándo de su expresión lingüística; pero, en la medida en que el hablante se proponga elevar su 
expresión verbal a una condición artística, en esa misma medida el necesario cauce de su discurso cederá en concreción identificadora, dejando su texto expedito para los amplios horizontes de lo simbólico, lo plurivalente, esencial a la creación estética en cuanto tal, como reconoce recientemente Umberto Eco, en su Lector in Fábula, Ed. Lumen, Barcelona, 1981, pág. 16: «Los textos que en aquel momento - se refiere a su Estructura ausente/Obra abierta- definia como «abiertos» son sólo el ejemplo más provocativo de explotación con fines estéticos de un principio que regula tanto la generación como la interpretación de todo tipo de texto". Lo que contrasta con el parecer de Lévi-Strauss, en Conversaciones con Lévi-Straus, Foucault e Lacán, Milán, 1969, pág. 81-82, citado por el propio Eco: «Lo que determina que una obra sea tal no es el hecho de ser abierta, sino el hecho de ser cerrada. Una obra es un objeto dotado de propiedades que el análisis debe especificar; un objeto que puede definirse completamente a partir de dichas propiedades. Así, pues, cuando Jakobson y yo -sigue diciendo Claude Lévi-Strauss - intentamos realizar el análisis estructural de un soneto de Baudelaire, no lo tratamos, por cierto, como una obra abierta, donde cabria hallar todo lo que las épocas posteriores podrían haber introducido en él, sino como un objeto que, una vez creado por su autor, adquirió, por decirlo así, la rigidez de un cristal: nuestra función se limitaba a explicitar sus propiedades."

Ya en Aspectos de semántica lingüístico-textual, tuve ocasión de mostrar mi parecer al respecto, a propósito de la multiplicidad de lecturas propugnada por R. Barthes en sus Mythologies. Sigo pensando que la legitimidad de una lectura o interpretación, de cualquiera de ellas, tiene como único umbral de justificación el texto de su cristalización terminal lingüistica. Pero la formalización a ultranza puede, perfectamente, pasar de lado sobre aspectos creativo-textuales, que no por no prestarse al fácil manejo de una rigurosa formalización, dejan de ser interpretables, como recientemente pone de manifiesto Nicolás Ruwet, en su Grammaire des insultes, Eds. du Seuil, París, 1981. Me parece una fácil consecuencia de la disminución de recursos de concreción identificadora que sirven de cauce al caudal discursivo de toda creación estético-verbal, cualesquiera que sean los mecanismos de fabulación empleados, incluso, mediante supuestas identificaciones extradiscursivas que, en su supuesta ejecutoria concreta o particular, terminan por no ser tales.

3.3.1.2. Los distintos tipos isotópicos obtenidos por identificación, en 
la variedad ya señalada, se ven multiplicados por infinidad de recursos morfosintáctico-semánticos, que surgen por doquier en el entramado relacional que todo texto comporta. Son los mecanismos que aseguran el marco de referencia donde adquiere sentido la imagen textual ofrecida por las estructuras semio-composicionales propiamente dichas. Tienen que ver, como ya señalamos anteriormente, con el quién/a quién, el dónde, el cuándo y el cómo de la producción/creación textuales. Entre los recursos morfosintáctico-semánticos instrumentados por los mecanismos de identificación, podemos destacar los siguientes:

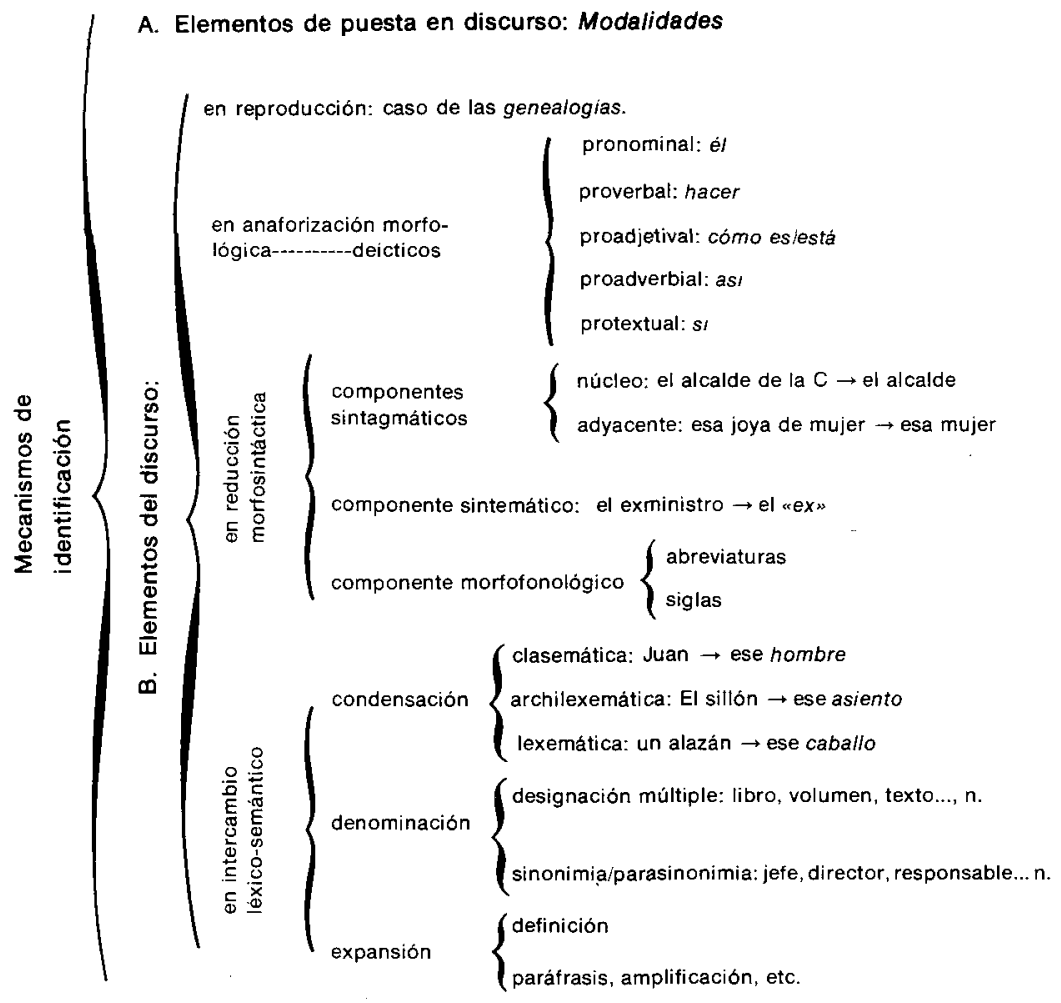


Tan variada gama de operadores de la identificación hacen posible el dinamismo de la estructura funcional de la lengua sin riesgos para los objetivos de la intencionalidad del yo textualizador, como hemos venido señalando.

4. Pero el cauce del flujo o caudal discursivo no está constituido, a mi juicio, sólo por los mecanismos de identificación, sino que, a menudo, viene enriquecido por mecanismos de la diversidad o disparidad, que confluyen en un "orden" o plan textual común, donde tanto lo similar como lo dispar tiene derecho a la existencia en virtud de la "dispositio" o planificación textual, «parium dispariunque rerum suacuique loca tribuens".

4.1. Recientemente en Estudios sintáctico-semánticos del Español-l. La Dinámica Interoracional, págs. $47-50$ y $58-72$, he hablado a propósito de tales mecanismos de la discrepancia o disparidad, aludiendo a ellos bajo la denominación de "nexos complejos" y "nexuación compleja". La problemática planteada en uno y otro lugar puede quedar estructurada en torno al siguiente esquema:

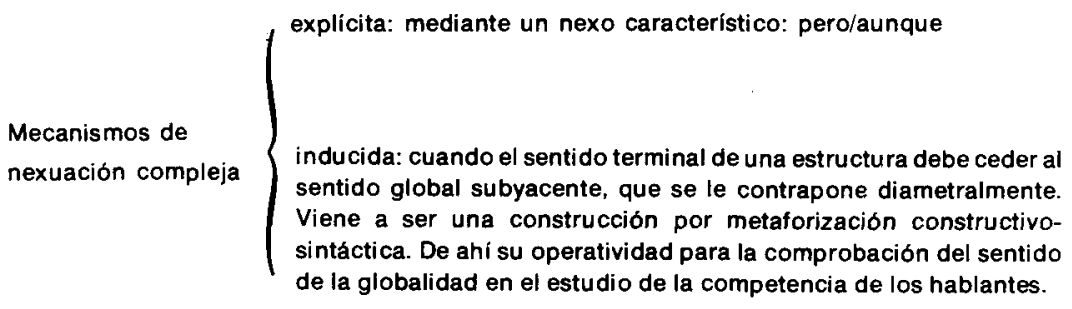

4.2. Repárese en el siguiente texto de A.R. Luria, en Fundamentos de neurolingüística, Toray-Massn, Barcelona, 1980, pág. 143: “El sentido de textos más complejos no puede ser reducido a tal secuencia y se precisa un proceso combinado de análisis y de síntesis y que incluya la 
comparación de fragmentos que en ocasiones están considerablemente separados en el tiempo, la creación de hipótesis del sentido general y, frecuentemente, la salida fuera de los límites del texto «externo" con el paso al "sentido figurado", que incluye en su composición la idea común de toda la expresión como un todo y en ocasiones la apreciación de los motivos que se ocultan tras el texto.

4.2.1. "Queda claro, podemos señalar con Luria, o.c.p. 145, que el proceso psicológico de la comprensión de tal texto se aparta de la simple decodificación de sus estructuras gramaticales individuales. Precisa la abstracción del significado particular, expresado por los elementos individuales del texto, sobre la comunicación que se transmite a partir de su "contenido exterior». El elemento más importante en la decodificación pasa a ser el análisis semántico interno del texto. La estructura psicológica de este último está casi totalmente sin estudiar». Nuestra propuesta, paralelamente a lo manifestado por Luria, consiste (habida cuenta de la indudable condición de sentido "global subyacente" que opera por debajo del "contenido exterior" de la construcción terminal de las frases sometidas a nexuación compleja inducida, según se ha puesto de manifiesto en Estudios sintáctico-semánticos del Español-lLa dinámica interoracional, págs. 68-72), en que merece la pena comprobar hasta qué punto determinados hablantes poseen o no el "sentido de la globalidad" textual, sometiéndolos al análisis de dichas construcciones, para ver si captan la ironía, el lamento, el énfasis, etc., que son su última razón de ser desde una perspectiva de lingüistica integral. La percepción de estos sentidos, en mi opinión, no es una cuestión de lectura paradigmática o suboracional, sino sintagmático-textual o interoracional, donde lo enunciado aparece vinculado a una especial responsabilidad enunciativa, que decide, en última instancia del sentido macroestructural dominante. Es lo que ocurre, a mi juicio, con microtextos del tipo:

Está demasiado pesado para venir corriendo;

Está demasiado atareado para venir con nosotros;

Está ya muy profundo para que pueda ser localizado con vida; etc.; ante las cuales, como ya tuve oportunidad de observar en el estudio arriba mencionado, no basta con una lectura sintagmática desde los datos de una paradigmática simple, sino que más bien hay que proceder a una lectura múltiple paradigmático-sintagmática morfosintáctico-semántica, e incluso pragmática, de cuyos datos se desprende una especial perspectiva prismática, o, como mínimo, en forma 
de cuadrado semiótico, desde donde tales microtextos quedan relativizados en su lectura superficial suboracional en aras de la lectura macroestructural subyacente, en virtud de la cual el sentido enfáticoirónico de tales microtextos puede servir de apoyo a la consideración de tales estructuras como anti-finales o finales adversativas, en el sentido de que no es el camino de la lógica implicatura el elegido, sino el de la contradicción lógico-pragmática. El que me atrevo a llamar síndrome atextual, interpretando a Luria, puede, a mi juicio, ser evidenciado ante microtextos de este tipo, pues, en efecto, sostengo la hipótesis de que dichas construcciones poseen en síntesis todos los ingredientes cualitativos de la función textual en su integridad. Lo cual puede, desde luego, evidenciarse en cualquiera de las metáforas de cualquier poemilla, cuyo ultrasentido paradigmático-sintagmático, a pari, tampoco será evidente para los sujetos sometidos al síndrome atextual. Se trata de un procedimiento distinto, en cuanto a su construcción, pero de efectos similares desde el punto de vista de la valoración de la capacidad de su percepción. 